\title{
UTILIZING NEURAL NETWORKS TO ASSESS COMMUNITY-LEVEL VULNERABILITY TO THE METHAMPHETAMINE EPIDEMIC
}

\author{
Cretson L. Dalmadge, Winston-Salem State University, dalmadgec@wssu.edu \\ Monica Cain, Winston-Salem State University, cainm@wssu.edu
}

\begin{abstract}
This study presents a practical framework for modeling community-level vulnerability to the methamphetamine epidemic. The study used 20032005 county-level methamphetamine laboratory seizure data and community characteristics as risk factors to develop a neural network model of the vulnerability to methamphetamine manufacture for each county in the United States. We categorized counties' meth problem as low ("Os"), intermediate ("1s"), and high ("3s") based on the number of seizures per year. Twenty community-level characteristics drawn from the Area Resource File (2004) are used as risk factors. We attained relative weightings for these factors and correctly classified 89.72 percent on the training data and correctly predicted 89.47 percent on the portion of the dataset reserved for testing.
\end{abstract}

\section{INTRODUCTION}

Illicit drug use in communities often leads to a complexity of issues involving addiction, distribution, crime, and manufacturing. Each drug has its own pattern of uptake and proliferation. Public health and public safety officials need to understand whether or how the next wave of illicit drugs will affect their communities.

The so-called "meth epidemic" is a recent example of a wave of drug use that ravaged some communities while leaving others untouched. Methamphetamine use and manufacture are commonly thought to have had its origins on the West Coast of the United States. The eventual spread eastward hit the Midwest states particularly hard, yet barely affected many states in the Northeast (NACO, July 2005). The degree of vulnerability appears to be influenced by community and population characteristics (Joon and Johnson 2001, Rodriguez et al., 2005, Pennell et al., 1999, Oetting et al., 2000).

Our goal is to provide a practical framework for modeling community-level vulnerability to future public health and safety threats, using the recent example of the methamphetamine epidemic. This study uses 2003-2005 county-level methamphetamine laboratory seizure data and community characteristics to develop a neural network model of the vulnerability to methamphetamine manufacture for each county in the United States.

Neural network modeling is increasingly used in public health and medicine but has not been applied to this specific problem. Examples include the prediction of diagnoses, clinical outcomes, genetic probabilities, and survival rates (Alkan et al, 2005; Baxt, 1991; Buchman et al., 1994; Goss \& Vozikis, 2002; Subasi and Ercelebi, 2005).

\section{THE SCOPE OF METHAMPHETAMINE IMPACT}

The National Association of Counties (NACO) released a 2005 survey detailing the county-level challenges that methamphetamine manufacture presents (NACO, July 2005). States reporting an increase in methamphetamine-related arrests during the previous five years included Arizona, Arkansas, Florida, Indiana, Iowa, Louisiana, Minnesota, Mississippi, Nevada, Ohio, Oklahoma, Oregon, South Carolina, Tennessee, Utah, Washington, and Wyoming, all reporting a 100\% increase; Georgia, reporting a 96\% increase; Colorado and Missouri, reporting a 95\% increase; South Dakota and Kansas, reporting a 94\% increase; and Idaho, California, and Montana, reporting a $90 \%$ increase. Clearly, methamphetamine is no longer a localized or regional issue. Only the Northeastern United States remains relatively unaffected.

\section{County Characteristics}

Earlier literature on crime relies on social disorganization theory. This theory maintains that economic, community, and family structure are related to crime (Bursik 1988). Poor economic activity, population density, racial and ethnic heterogeneity, and residential instability are characteristics of socially disorganized communities. 
This literature indicates a strong association between crime and disorganized communities.

Several studies address the relationship between community characteristics and drug use. Esbensen and Huizinga (1990) used self-reported data from the Denver Youth Study. Study data on youth behavior and drug use was linked to U.S. Census data for the Denver area. The researchers examined the effects of community-level characteristics on marijuana use using bivariate analyses. Several community-level factors were used based on the theory of social disorganization theory, including age, marital status, employment, housing, ethnicity, family structure, and residential instability. They found that marijuana use was greater for young people living in high population density areas where there were large numbers of unemployed individuals and large numbers of individuals employed as service workers and laborers.

Most studies have focused on community-level characteristics and youth drug use, specifically marijuana and/or other substance abuse, in a single location. Rodriguez et al. (2005), however, examines the impact of individual, community, and market factors on methamphetamine use among a sample of adult male arrestees. This study uses hierarchical generalized linear models to describe the effects of these factors in a comparison of two counties, Maricopa and Pima in Arizona. The study links data from the Arrestee Drug Abuse Monitoring (ADAM) program for years 2000-2003 to zip code-level data from the 2000 U.S. Census. Five community-level factors, drawn from the census data, are used in the model: unemployment levels, percentage of county population completing high school, the percentage of county population completing college, a racial/ethnic heterogeneity index, and the percentage of Spanishspeaking households.

Three of these factors were found to significantly influence the rate of methamphetamine use. A higher percentage of college-educated residents and Spanish-speaking households in a community were associated with lower levels of methamphetamine use. Higher unemployment rates were correlated with lower levels of methamphetamine use. High levels of ethnic/racial heterogeneity and high percentages of high school-only education were insignificant factors. These findings suggest that community-level factors typically used as predictors of drug use in social disorganization theory-high unemployment, racial/ethic heterogeneity, and lower levels of education-do not help to identify those communities vulnerable to methamphetamine abuse.
Interestingly, Rodriguez et al. find that communitylevel predictors of methamphetamine use, in fact, differ significantly from marijuana, cocaine, and opiate use.

While this study explains some of the differences in methamphetamine use between the two counties, it concludes that "unmeasured differences between the counties remain unexplained in the model.” Another limitation of the study is that the results cannot be generalized because of the comparison between just two locales and the adult, male-only sample of arrestees.

\section{Individual Characteristics}

We believe that earlier research on the individual characteristics of methamphetamine users may point to additional community composition factors for use in our proposed study. Most of the literature focuses on socio-demographic factors such as race, age, gender, income, and housing. Pennell et al. (1999) used ADAM data, interviews, and urinalysis from arrestees in five western cities--Los Angeles, San Diego, and San Jose in California; Phoenix, Arizona; and Portland, Oregon - for the period October 1996September 1997. The majority of methamphetamine users were white, ranging from $54 \%$ in San Jose to 94\% in Portland, however Hispanic use was increasing. Among African-Americans arrestees, only $1 \%$ in Phoenix and $11 \%$ in San Diego tested positive for methamphetamines. One-third of the arrestees were women, and the average age of all methamphetamine users in the study was 30 years old. Among juvenile users in all five cities, 47\% were Hispanic and $41 \%$ were White.

Oetting et al. (2000) used the American Drug and Alcohol Survey of 600,000 students to identify individual characteristics of methamphetamine users. They found that while female use has increased, males are more likely to be methamphetamine users among high school students. Native Americans and Hispanics are most likely to be methamphetamine users, followed by Asians and Whites. AfricanAmericans were the least likely to use.

In another study using ADAM arrestee data, Herz (2000) compared individual characteristics among methamphetamine users to non-users in communities of Nebraska in 1998. This study reported that users were most likely to be White and to live in privatesector housing rather than public-sector housing. Methamphetamine users and non-users did not differ in age and education. Users were as equally likely to reside in rural or urban settings, but rural users were 
slightly younger than urban users. Whether they used methamphetamine or not, arrestees tended to be single.

The study by Rodriguez et al. (2005) of adult male arrestees in two Arizona counties found that age was negatively correlated with methamphetamine use. Hispanic, Native American, and African-American arrestees were all more likely to test positive for methamphetamine use than Whites. Unemployed arrestees and violent offenders were more likely to use methamphetamines. Education and marital status had no effect on methamphetamine use.

\section{Methamphetamine Markets}

Researchers paint very different pictures of the market for methamphetamine and the market for other drugs. These differences may lead us to hypotheses about the types of communities in which methamphetamine markets may emerge. For example, Eck (1995) reports that in his study of the San Diego market methamphetamine dealers were more likely to sell within a social network while other drug dealers sold to strangers. Methamphetamine dealers were more likely to sell out of single-family homes that were spread out across the community in contrast to markets for other drugs which are more geographically concentrated. Similarly, Pennell et al. (2000) found that methamphetamine markets are closed, relying on a social network where sales to strangers are uncommon. In fact, users reported abstaining from the drug if they could not obtain it from their usual source. Methamphetamine market transactions typically occur indoors, rather than outside on the street as may be the setting for the sale of other drugs.

Rodriguez et al. (2005) conclude that conventional measures of drug markets (open markets, source, and price) are less important in determining methamphetamine use than are individual and community characteristics. The researchers attempted to aggregate measures of the drug market by zip code, but small cell count prohibited using zip code-level aggregation in their models. As a result, the county is the smallest unit of analysis to which market data can be aggregated in their study. The findings of this study point to communities whose particular characteristics foster methamphetamine markets, specifically younger, White, unemployed males in non-Hispanic communities where employment and education levels are high.
If, as these studies suggest, methamphetamine markets are closed and local, relying on a social network for distribution, then manufacture and use will likely coexist in local geographic markets. Users may be willing to access proximate methamphetamine suppliers in contiguous counties, but would be less likely to rely upon distant, unknown sources of the drug. This preference suggests that until local "small lab" manufacture of methamphetamine is disrupted, users will be less inclined to seek out substitutes such as "large lab" Mexican crystal methamphetamine.

\section{THE DATA}

Given that there are no precise measures of methamphetamine manufacture in a given county or state, we utilize laboratory seizures as a proxy for production levels. The U.S. Drug Enforcement Administration (DEA) El Paso Intelligence Center has released data from its Clandestine Laboratory Surveillance System (CLSS) to the research team. The CLSS gathers information on lab seizures from local, state, and federal law enforcement agencies. To be classified as a methamphetamine laboratory seizure, the incident must include the seizure of a sufficient combination of equipment and chemicals that either has been or could be used in the manufacture of methamphetamine (U.S. DEA, 2006). Each CLSS observation describing the seizure of a methamphetamine laboratory includes the date, state, and county. No unique personal identifiers were released. This data file contains all methamphetamine laboratory seizures reported to CLSS for every county in the United States during 2001-2005 $(n=76,569)$. While this data file includes only seizures actually reported through CLSS, it is purported to be the most comprehensive data file of its kind.

The second data file used in the study is the Area Resource File (2004). We extracted selected fields of county-level characteristics from the 2000 U.S. Census and county-level health service resources data (See Table 3 in Appendix).

The data received from the CLSS system was in the form of PDF documents (600 - 700 pages for each year). Using optical character recognition software, we converted this to MS Excel format. After cleaning the files, we imported them into MS Access and used database queries to link the lab seizure data with the county-level data.

To link the CLSS data and county-level data, the Federal Information Processing Standards (FIPS) 
code was used. This is a five-digit code identifying a state and county. Based on the existing county and state fields in the CLSS data file, we inserted the corresponding five-digit FIPS code for every lab seizure observation. This common field allowed us to link each of the CLSS county-level seizure observations with the county-level characteristics. The result is a comprehensive data set on all 3,143 counties in the Unites States for years 2001-2005.

We aggregated the linked observations by year, state, and county. In addition, we restricted our analysis to 2003-2005, the peak years of methamphetamine seizures and the period prior to the passage of any precursor law legislation. This resulted in a data set of 9,427 observations. The data was saved as comma separated variable (CSV) to facilitate the work in NeuroShell Classifier.

\section{MODELING THE VULNERABILITY INDEX}

The results of the earlier studies cited above point to specific risk factors influencing the likelihood of manufacture and distribution of methamphetamine. Having examined this consistent identification of specific factors, we pose the question "Is there a group/set of factors that collectively determines the risk that a given community faces with regards to the production and usage of methamphetamine?" We posit that it is possible to identify and quantify the relative importance of these factors. The rest of the paper addresses the development and testing of the model.

\section{The Risk Factors}

The central thesis of our work is that county-level characteristics are capable of serving as indicators of the vulnerability of the said county to the risk of methamphetamine manufacture. Our work is inspired by the use of risk factor in the medical sciences and business but does not attempt to exactly mirror any of those studies. Both disciplines have had success in utilizing risk factors in quantifying the vulnerability measures.

The use of risk factors has found broad acceptance in most of the medical discipline. This was initiated by the study of heart disease by the Framingham group. Subsequent works have utilized risk factors to address issues ranging from cancers and HIV to gambling (Hamel 2007, Park 2007). Indeed, studies in HIV transmission have identified methamphetamine usage as a risk factor (Mahmood
2007). In this paper we address the other side of the problem, that is, "Is there a definitive list of risk factors that are collectively capable of predicting the risk of methamphetamine manufacture in a given county?”

The results of the earlier studies discussed and cited above supports the position that addicts are far more successful in generating production in some counties than in others. Our thesis is that these factors collectively define the county's likelihood that it will fall prey to the manufacture of methamphetamine. As such, these factors effectively serve as risk factors for methamphetamine manufacture.

\begin{tabular}{|c|c|c|c|c|c|c|c|c|}
\hline Housing & $\begin{array}{l}\text { Incomel } \\
\text { Poverty }\end{array}$ & $\begin{array}{l}\text { Population } \\
\text { Density }\end{array}$ & Employment & $\begin{array}{l}\text { Health } \\
\text { Services }\end{array}$ & Education & Age & Ethnicity & $\begin{array}{l}\text { Existing } \\
\text { Problem }\end{array}$ \\
\hline $\begin{array}{l}\text { Modin } \\
\text { Homo } \\
\text { Vdien }\end{array}$ & $\begin{array}{c}\text { Ponitstunt } \\
\text { Povorty } \\
\text { Typo Cods } \\
\end{array}$ & $\begin{array}{l}\text { Population } \\
\text { Densalty per } \\
\text { Squen Hillo }\end{array}$ & $\begin{array}{c}\text { \%ollaws Did } \\
\text { Not Work, } \\
16+\end{array}$ & $\begin{array}{c}\text { Pilmay } \\
\text { Cant }\end{array}$ & $\begin{array}{c}\text { Yo Proons } \\
25+\text { Wh4t } \\
\text { Yrs } \\
\text { Collegs }\end{array}$ & $\begin{array}{l}\text { Wodlan } \\
\text { Ags, } \\
\text { Whito } \\
\text { Mndo }\end{array}$ & $\begin{array}{l}\text { Percunt } \\
\text { whow Pop }\end{array}$ & $\begin{array}{l}\text { County's } \\
\text { Prior } \\
\text { Year } \\
\text { Solatise }\end{array}$ \\
\hline $\begin{array}{l}\text { No of } \\
\text { Heusolhald } \\
\text { swith1 } 1 \\
\text { Porsons }\end{array}$ & $\begin{array}{c}\text { Por Caplita } \\
\text { heome }\end{array}$ & & $\begin{array}{c}\text { Yoandol } \\
\text { Ded Not } \\
\text { Work, 16+ }\end{array}$ & $\begin{array}{l}\text { Montal } \\
\text { Hoct' }\end{array}$ & 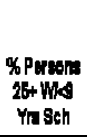 & & $\begin{array}{c}\text { Percint } \\
\text { Blockith } \\
\text { Ean } \\
\text { Americen } \\
\text { Pep }\end{array}$ & 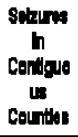 \\
\hline \multirow[t]{2}{*}{$\begin{array}{c}\text { YoFarilloa } \\
\text { wth } \\
\text { Fomalo } \\
\text { Head }\end{array}$} & & & \multirow[t]{2}{*}{$\begin{array}{l}\text { Unemploym } \\
\text { ent Rete, 16+ }\end{array}$} & & & & $\begin{array}{c}\text { Percent } \\
\text { Amorlcen } \\
\text { hidantila } \\
\text { wa kattwo } \\
\text { Pop }\end{array}$ & \\
\hline & & & & & & & $\begin{array}{c}\text { Percent } \\
\text { Plapan'l] } \\
\text { Litno } \\
\text { Pop }\end{array}$ & \\
\hline
\end{tabular}

Figure 1: Risk Factors for Meth Manufacture

Drawing on theorization and existing evidence, we have developed a taxonomy for studying the risk faced by counties with regards to methamphetamine manufacture. The elements of the taxonomy are modeled in Figure 1. The classification shows nine high-level factors influencing the risk of methamphetamine manufacture. These are housing, poverty level, population density, employment, health services available to the residents of the counties, education levels, age, race/ethnicity and pre-existing levels of methamphetamine-related problems.

Each of the nine categories in Figure 1 is supported by lower level variables. In most cases multiple supporting variables are utilized. In two cases, population density and age, single indicators are utilized in the model. This was necessary to avoid the high level of correlation between independent variables - detrimental in the use of neural network modeling. Population density, for example has other indicators such as housing density per square mile. 
This is almost perfectly correlated with population density per square mile.

\section{The Methodology}

Data mining tools such as artificial neural networks are renowned for their ability to uncover relationships between the elements in a data set. These relationships may be well established or previously unknown. Using the popular artificial neural network tool NeuroShell Classifier, we studied the relationship between the 20 independent variables shown in Figure 1 and the manufacture levels of methamphetamine in the counties (as the dependent variable). NeuroShell Classifier was selected as the tool of choice because of its ability to show the relative weightings/contributions of the individual inputs. Hence, we are provided with the relative contribution of the independent variables in the study. Most other neural networks packages on the market provide data on the quality of the classification model without showing the relative contributions of the each input.

\section{The Classification Matrix}

The dependent variable (actual lab seizures) varied from a low of zero in some counties to a high of 521 in one county. Mapping the actual lab seizures would result in an extremely large matrix. The research design, therefore, does not facilitate the usage of actual seizures. Instead, data may be broken into categories, for example, desirable results vs. undesirable results. Clearly a desirable result here would be zero production of methamphetamine with all other levels being undesirable. Preliminary analysis of the dataset showed no significant difference between counties with zero seizures per year and those with very low numbers such as 1,2 or 3 seizures per year.

\begin{tabular}{|c|c|c|c|}
\hline & Actual "0" & Actual "1" & Actual "2" \\
\hline Classified as "0" & yes & $\mathrm{N}$ & $\mathrm{N}$ \\
\hline Classified as "1" & $\mathrm{N}$ & yes & $\mathrm{N}$ \\
\hline Classified as "2" & $\mathrm{N}$ & $\mathrm{N}$ & yes \\
\hline
\end{tabular}

Figure 2: The Classification Matrix

Based on the results on preliminary statistics, we chose a three step classification. " 0 " represents counties that averaged less than one seizure per month, that is, less than twelve lab seizures per year. " 1 ' represent counties that averaged more than one seizure per month but less than one per week, that is, twelve to fifty-one lab seizures per year. "2" represent counties that averaged one or more seizures per week, that is, fifty-two or more lab seizures per year.

Figure 2 shows the classification matrix. Our analysis will focus on the level of accuracy in the classification matrix. In a perfect scenario, all the Actual "O" will be classified as "O", similarly for the "1s" and " $2 \mathrm{~s}$ ". That is, cells marked "yes" are properly classified and those marked $\mathrm{N}$ represent incorrect classification.

\begin{tabular}{|c|c|c|c|}
\hline & Actual "O" & Actual "1" & Actual "2" \\
\hline $\begin{array}{c}\text { Classisfied } \\
\text { as "0" }\end{array}$ & 0 & -6 & -12 \\
\hline $\begin{array}{c}\text { Classisfied } \\
\text { as "1" }\end{array}$ & -1 & 0 & -4 \\
\hline $\begin{array}{c}\text { Classisfied } \\
\text { as "2" }\end{array}$ & -3 & -1 & 0 \\
\hline
\end{tabular}

Figure 3: Fitness Coefficient Matrix

Figure 3 shows the weighting associated with misclassification of the variables. Because the " $0 \mathrm{~s}$ " dominated the dataset, an un-weighted design yielded very high overall prediction scores but included almost 100 percent correct classification of the " $0 \mathrm{~s}$ " and less than 20 percent for the " $1 \mathrm{~s}$ " and " $2 \mathrm{~s}$ ". We elected to use the Advanced Genetic option, with distinct weightings for (mis)classification. If a " 2 " is classified as a zero it has a higher impact on the overall model than if it is classified as a " 1 ".

\section{THE RESULTS}

Data was inputted to NeuroShell Classifier for the three year period 2003-05. This resulted in 9427 lines

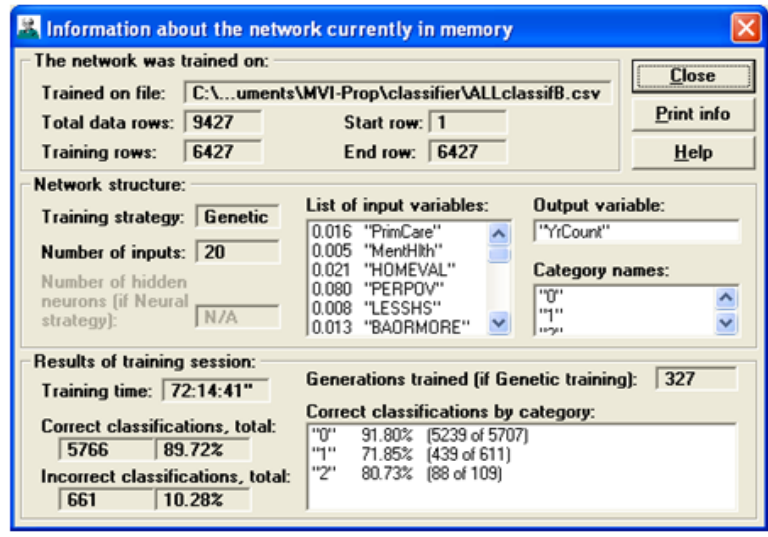

Figure 4: The NeuroShell input Information 
of data for potential analysis. We broke this into a training set of 6427 and a test set of 3000 lines of data. The package was configured, and the PC allowed to run without hibernating. The run was interrupted when there was no further evidence of improvements in the training of the system (i.e. learning was completed). The actual run for the data set took 72.25 hours and produced 89.72 percent correct predictions on the learning portion of the dataset.

Figure 4 shows the accuracy of the model on the training data. 91.8 percent of the " $0 \mathrm{~s}$ " were correctly predicted as " 0 s", 71.8 percent if the " 1 " " were correctly predicted as " $1 \mathrm{~s}$ " and 80.7 percent of the “2s" were correctly predicted as " $2 \mathrm{~s}$ ".

The trained network was then tested against the data held for testing the quality of the model. Figure 5 shows the results this test. In total 2684 of the 3000 cases were accurately predicted (89.47 accuracy). This broke down into 2441 of the 2655 "0s" (i.e. 91.94 percent), 191 of the 286 " $1 \mathrm{~s}$ " (i.e. 66.78 percent) and 52 of the 59 " 2 s" (i.e. 88.14 percent) being accurately predicted.

Since "0s" represent the best case scenario, " $1 \mathrm{~s}$ " the intermediate case and " $2 \mathrm{~s}$ " represent the worst case scenario, there would be grave concerns if large number of " $0 s$ " were being predict to be " $2 s$ " or " $2 s$ " predicted as "0s". Figure 5 shows that only 4 times in the 3000 cases did this occur.

\begin{tabular}{l}
\hline Agreement Matrix [Contigency Table] Statistics: \\
\begin{tabular}{|l|c|c|c|c|}
\hline & $\begin{array}{c}\text { Actual } \\
\text { "0" }\end{array}$ & $\begin{array}{c}\text { Actual } \\
\text { "1" }\end{array}$ & $\begin{array}{c}\text { Actual } \\
\text { "2" }\end{array}$ & Total \\
\hline $\begin{array}{l}\text { Classified as } \\
\text { "0" }\end{array}$ & 2441 & 57 & 0 & 2498 \\
\cline { 1 - 1 } $\begin{array}{l}\text { Classified as } \\
\text { "1" }\end{array}$ & 210 & 191 & 7 & 408 \\
\cline { 1 - 1 } $\begin{array}{l}\text { Classified as } \\
\text { "2" }\end{array}$ & 4 & 38 & 52 & 94 \\
\hline Total & 2655 & 286 & 59 & 3000 \\
\hline
\end{tabular}
\end{tabular}

Figure 5: Results from testing the model

\section{Relative Importance of the Input Variables}

The contribution of each of the twenty items is shown in Table 1. Percentage contribution is reported in descending order and cumulative percentage is also provided. As shown in the table, prior year seizures account for 27.4 percentage of the variance. The next major contributors were percentage of 'blacks in the population' with 19.4 percent, the percentage of homes with female as head of household with 16 percent, and poverty level in the county at $8 \%$. Together these four factors accounted for 71 percent of the variance in the analysis. Other significant contributors include 'percentage of North American Indian in the population' at 5.7 percent and 'per capita income levels' at 3.9 percent.

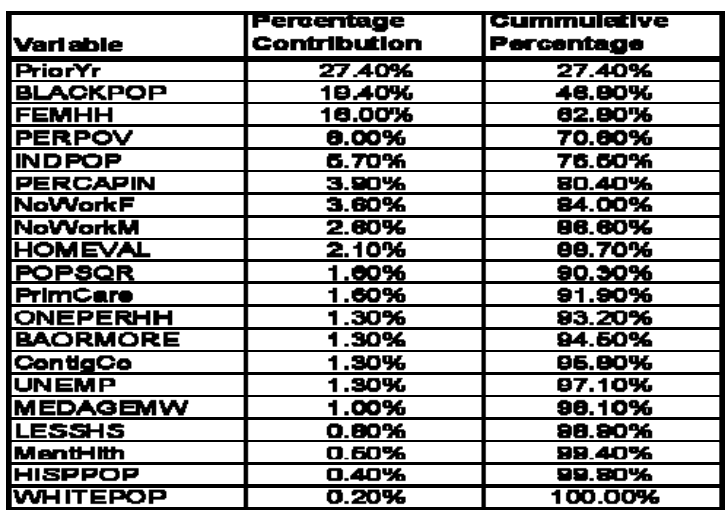

Table 1: Contribution of the Individual Inputs

\section{The ROC Curves}

The receiver operating characteristics (ROC) curves are presented in Figure 6. ROC curves show the accuracy of classification (i.e. percent of true positive to false positive for the model). The choice of a 3X3 matrix (rather than the conventional 2X2) resulted in multiple ROC curves outputted by the software.

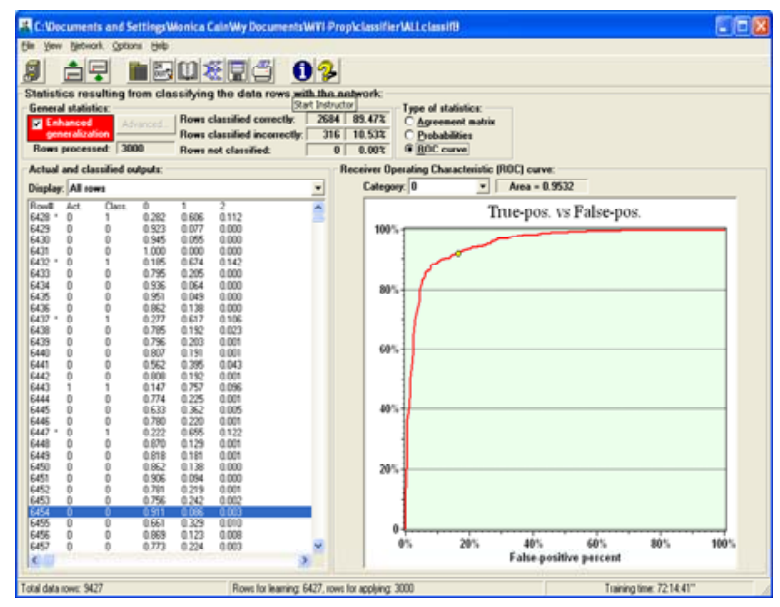

Figure 6: ROC Curves for the "Os" 
Area under ROC curves vary from 0.5 (representing no discrimination), to 1.0 representing perfect discrimination (Flaherty and Patterson, 2003). As seen in Figure 6, the area under ROC curves for the " 0 s" was 0.95 . In the interest of brevity, we are unable in include diagrams for the ROC curves " $1 \mathrm{~s}$ " and " $2 \mathrm{~s}$ ". The outputted results were 0.89 and 0.98 respectively.

\section{DISCUSSION}

In this study we developed a neural network model of the vulnerability to methamphetamine manufacture for U.S. counties. We used a set of factors based on county-level characteristics to predict the risk of methamphetamine manufacture. Our intent was to provide a practical framework for modeling community-level vulnerability to future public health and safety threats, using the recent example of the methamphetamine epidemic.

Our review of earlier studies provided the basis for selecting appropriate variables for our model. In addition, we created two variables to represent the methamphetamine experience that the county currently faced. First, we used the county's prior year seizure information as a risk factor for the current year. We also created a variable to measure the level of methamphetamine manufacture occurring in contiguous counties, with the expectation that a county surrounded by high risk counties would be at higher risk, and vice versa.

We developed the criteria to classify counties as " $0 \mathrm{~s}$ ”, " $1 \mathrm{~s}$ ", and " $2 \mathrm{~s}$ " through trial and error. It was obviously important that we represent the very large number of counties with zero or only a few laboratory seizures per year as clearly differentiated from those counties that had extremely high yearly counts. This required that our efforts be focused on defining the middle classification, that is, the " $1 \mathrm{~s}$ ". We finally determined that this intermediate classification should be defined as counties that averaged more than one seizure per month but less than one per week, that is, twelve to fifty-one lab seizures per year. Several alternative cut-offs were tested, but these yielded less accurate classifications.

Another challenge we faced was carefully choosing the appropriate weights so that grave misclassification errors were minimized. Each time a new weighting scheme was developed, it required the model to be re-trained and tested. As noted above, this process took days, not hours, to complete because of the large number of observations and risk factors. The final neural network model correctly classified the "0s" (89\%), the " $1 \mathrm{s"} \mathrm{(67 \% ),} \mathrm{and} \mathrm{the}$ " $2 \mathrm{~s}$ " $(88 \%)$. While the classification accuracy of the intermediate case is somewhat low, we believe that the achievement of accurate classification of the bestcase and worse-case scenarios is much more important.

One of the objectives of this study was to assess whether the categories of community-level threats identified in the earlier literature would be effective in predicting the level of vulnerability using a neural network approach. Table 2 demonstrates that the factors related to just five categories alone contributed over $90 \%$ to the prediction of the threat of methamphetamine manufacture.

\begin{tabular}{|l|c|c|}
\hline FACTOR/DIMENSION & $\begin{array}{c}\text { PERCENTACE } \\
\text { CONIRIBUTION }\end{array}$ & $\begin{array}{c}\text { QUMUATIVE } \\
\text { PERCENTAGE }\end{array}$ \\
\hline EXISTINGPRCBLFM & 28.7 & 28.7 \\
\hline ETHNCTY & 25.7 & 54.4 \\
\hline HOSING & 19.4 & 73.8 \\
\hline INCOMEIPOVERTY & 119 & 85.7 \\
\hline EMPLOYMENT & 7.5 & 93.2 \\
\hline HEALTHSERMCES & 2.1 & 95.3 \\
\hline EDUCATON & 2.1 & 97.4 \\
\hline POPUATIONDENSTY & 1.6 & 99.0 \\
\hline AGE & 1.0 & 100.0 \\
\hline
\end{tabular}

Table 2: Contribution of Each Factor

There are several limitations to this study. The first limitation relates to the results generated by the software package. NeuroShell Classifier does not report the direction of the influence of each variable, only its percentage contribution. We are not able to determine from the computer-generated results, therefore, whether there is a positive or a negative relationship between methamphetamine lab seizures and each of the risk factors. Much of what we do know about the direction of relationship of these risk factors to methamphetamine comes from the earlier studies, as described above, and our own supplemental regression analysis.

Another limitation of the study is related to the CLSS data. This data file includes only seizures actually reported through CLSS system. It is possible that methamphetamine laboratory seizures are missing because of incorrect identification, lack of local law enforcement resources, or failure to report seizures to the DEA. Despite this potential for missing observations, the CLSS data file is purported to be the best of its kind.

This study uses neural network modeling in a public health/public safety context. We hope to encourage 
researchers to expand applications of this type of modeling in other areas of community research.

\section{REFERENCES}

1. Alkan, A., Koklukaya, E. \& Subasi, A. Automatic seizure detection in EEG using logistic regression and artificial neural network. Journal of Neuroscience Methods 2005; 148(2), 167-176.

2. Arthur, M., Hawkins, J. Pollard, J., Catalano, R. and Baglioni, A. Measuring risk and protective factors for substance abuse, delinquency, and other adolescent problem behaviors: The Communities That Care Survey. Evaluation Review 2002; 26: 575-601.

3. Baxt, W.G. Use of an artificial neural network for the diagnosis of myocardial infarction. Annals of Internal Medicine, 1991; 115(11), 843-848.

4. Buchman, T.G., Kubos, K.L, Seidler, A.J \& Siegforth, M.J. A comparison of statistical and connectionist models for prediction of the chronicity in a surgical intensive care unit. Critical Care Medicine, 1994; 22(5), 750-762.

5. Bursik, R. Social disorganization and theories of crime and delinquency: Problems and prospects. Criminology, 1988; 26: 519-552.

6. Eck, J. A general model of the geography of illicit retail marketplaces. In J. Eck and D. Weisburd, Editors, Crime and Place: Vol. 4, Monsey: Criminal Justice Press.

7. Esbensen, F., and Huizinga, D. Community structure and drug use: From a social disorganization perspective. Justice Quarterly, 1990; 7: 691-709.

8. Fleming, S. The Meth Effects. American City and County, (2005): 42-46.

9. Goss, E. \& Vozikis, G.S. Improving Health Care Organizational Management Through Neural Network Learning. Health Care Management Science, 2002; 5(3), 221-227.

10. Herz, D. Drugs in the heartland: Methamphetamine use in rural Nebraska. 2000; Washington D.C.: National Institute of Justice.

11. Joon, S., Johnson, B. Neighborhood disorder, individual religiosity, and adolescent use of illicit drugs: A test of multilevel hypothesis. Criminology, 2001; 39: 109-143.

12. Mahmood SA., HIV/AIDS in Bangladesh: the role of government in health and human services administration. Journal of Health and Human Services Administration. Harrisburg: Fall 2007. Vol. 30, Iss. 2; p. 129

13. National Association of Counties, July 5, 2005, The Meth Epidemic in America, Two surveys of U.S. Counties: The Criminal Effect of Meth on Communities and The Impact of Meth on Children.

14. National Association of Counties, July 18, 2006, The Meth Epidemic in America, The Criminal Effect of Meth on Communities, A 2006 Survey of U.S. Counties.

15. Park, A., Breast-Cancer Basics. Time. New York: Oct 15, 2007. Vol. 170, Iss. 16; p. 46

16. Pennell, S., Ellett, J., Rienick, C., and Grimes, J. Meth matters: Report on methamphetamine users in five western cities. 1999; Washington D.C., National Institute of Justice.

17. Rodriguez, N., Katz, C., Webb, V., and Schaefer, D. Examining the Impact of Individual, Community, and Market Factors on Methamphetamine Use: A Tale of Two Cities. The Journal of Drug Issues, 2005; 35: 656-693.

18. Subasi, A. \& Ercelebi, E. Classification of EEG signals using neural network and logistic regression. Computer Methods and Programs in Biomedicine, 2005; 78(2), 87-99.

19. Swalwell, C., and Davis, G.: "Methamphetamine as a risk factor for acute aortic dissection," Journal of Forensic Sciences. 44(1): 23-26, 1999.

20. U. S. Drug Enforcement Administration, State Factsheets, Washington D.C., Department of Justice, (2006).

21. Van Hamel, A., Jeffrey Derevensky, Yoshio Takane, Laurie Dickson, Rina Gupta. Adolescent Gambling and Coping within a Generalized High-risk Behavior Framework, Journal of Gambling Studies. New York: Dec 2007. Vol. 23, Iss. 4; p. 377-93 


\section{APPENDIX}

Table 3: Study Variable Descriptions

\begin{tabular}{|c|c|c|}
\hline Category/Variables & Description & Variable Name \\
\hline \multicolumn{3}{|l|}{ Meth Seizure Experience } \\
\hline Prior year seizures & Yearly count in prior year & PriorYr \\
\hline Contiguous Counties & Yearly count in contiguous counties & ContigCo \\
\hline \multicolumn{3}{|l|}{ Housing } \\
\hline Median Home Value & Median Home Value (2000) & HOMEVAL \\
\hline Households with 1 Person & Number of Households with 1 Persons (2000) & ONEPERHH \\
\hline $\begin{array}{l}\text { \% Families with Female } \\
\text { Head }\end{array}$ & Percent of Families with a Female Head (2000) & FEMHH \\
\hline \multicolumn{3}{|l|}{ Income/Poverty } \\
\hline Persistent Poverty Code & $\begin{array}{l}\text { Poverty-level county income in the preceding year were } \\
20 \text { percent or more of total population in each of } 4 \text { years: } \\
1960,1970,1980,19900=\text { no; } 1=\text { yes }\end{array}$ & PERPOV \\
\hline Per Capita Income & Per Capita Income (2001) & PERCAPIN \\
\hline \multicolumn{3}{|l|}{ Population Density } \\
\hline Population Density & Population per Square Mile (2000) & POPSQR \\
\hline \multicolumn{3}{|l|}{ Employment } \\
\hline$\%$ Males not working & $\begin{array}{l}\text { Percent of Males Did Not Work, } 16 \text { or more years old } \\
\text { (1999) }\end{array}$ & NoWorkM \\
\hline \% Females not working & $\begin{array}{l}\text { Percent of Females Did Not Work, } 16 \text { or more years old } \\
\text { (1999) }\end{array}$ & NoWorkF \\
\hline Unemployment rate & Unemployment Rate, 16 or more years old (2002) & UNEMP \\
\hline \multicolumn{3}{|l|}{ Health Services } \\
\hline Primary Care & $\begin{array}{l}\text { Health Professional Shortage Area Code - Primary Care; } \\
\text { 0: none, 1: full, 2: partial. (2003) }\end{array}$ & PrimCare \\
\hline Mental Health & $\begin{array}{l}\text { Health Professional Shortage Area Code - Mental Health; } \\
\text { 0: none, 1: full, 2: partial. (2003) }\end{array}$ & MentHlth \\
\hline \multicolumn{3}{|l|}{ Education } \\
\hline$\%$ with $>4$ years college & $\begin{array}{l}\text { Percent of Persons } 25 \text { years or older with } 4 \text { or more Years } \\
\text { College (2000) }\end{array}$ & BAORMORE \\
\hline$\%$ with $<9$ years schooling & $\begin{array}{l}\text { Percent of Persons } 25 \text { years or older with less than } 9 \\
\text { Years School (2000) }\end{array}$ & LessHS \\
\hline \multicolumn{3}{|l|}{ Age } \\
\hline Median Age, white male & Median Age, White Male (2000) & MEDAGEMW \\
\hline \multicolumn{3}{|l|}{ Race/Ethnicity Population \% } \\
\hline \% White & & WHITEPOP \\
\hline \% African American & & BLACKPOP \\
\hline \% American Indian/Alaskan & & INDPOP \\
\hline \% Hispanic/Latino & & HISPPOP \\
\hline
\end{tabular}

